\title{
Privatização da CASAL no contexto da mercantilização da água na América Latina
}

\author{
Tatiana Lyra Lima Félix ${ }^{1}$ \\ https://orcid.org/0000-0002-0775-6586
}

\author{
Artur Bispo dos Santos Neto ${ }^{2}$ \\ https://orcid.org/0000-0003-4669-096X
}

${ }^{1}$ Universidade Federal de Alagoas, Faculdade de Serviço Social, Programa de Pós-Graduação em Serviço Social, Maceió, AL, Brasil

${ }^{2}$ Universidade Federal de Alagoas, Departamento de Filosofia, Instituto de Ciências Humanas, Comunicação e Artes, Programa de Pós-Graduação em Serviço Social, Maceió, AL, Brasil

\section{Privatização da CASAL no contexto da mercantilização da água na América Latina}

Resumo: No decorrer deste texto buscar-se-á apreender a categoria da mercadoria no interior da teoria marxiana, como ponto de inflexão para a compreensão do processo de transformação da água e do serviço de saneamento básico em mercadoria. A partir da crítica marxiana ao sistema do capital, intenta-se desvelar a peculiaridade da privatização da Companhia de Saneamento Básico de Alagoas (Casal) e como esta se plasma enquanto elemento de aprofundamento da dependência econômica da América Latina em relação aos imperativos do sistema financeiro e às diretrizes dos organismos de fomento internacional, os quais têm como premissa essencial expandir os mecanismos de acumulação mediante a espoliação das riquezas hídricas. Palavras-chave: Mercadoria. Corporações transnacionais. Riquezas hídricas.

\section{Privatization of CASAL in the context of water marketing in Latin America}

Abstract: In the course of this text, we will seek to apprehend the category of merchandise within Marxian theory, as a turning point for understanding the process of transforming water and basic sanitation into merchandise. Based on the Marxian critique of the capital system, the intention is to unveil the peculiarities of the privatization of the Basic Sanitation Company of Alagoas (Casal) and how this plasma as an element of deepening Latin America's economic dependence on the imperatives of the financial system and the guidelines international development agencies whose essential premise is to expand the mechanisms of accumulation through the plundering of water resources.

Keywords: Merchandise. Transnational corporations. Water riches.

Recebido em 04.02.2021. Aprovado em 11.05.2021. Revisado em 07.07.2021.

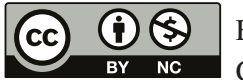

Este é um artigo publicado em acesso aberto (Open Access) sob a licença Creative Commons Attribution NonCommercial, que permite uso, distribuição e reprodução em qualquer meio, sem restrições desde que sem fins comerciais e que o trabalho original seja corretamente citado. 


\section{Introdução}

A água configura-se como um elemento fundamental para a emergência da vida no planeta Terra. Sem água inexistiria qualquer espécie de ser orgânico, por ser imprescindível à reprodução orgânica do ser social. Não à toa o filósofo Tales de Mileto (apud HEGEL, 1973) afirmou que a água era o princípio fundante de todas as coisas, pois ela estava contida em todas as coisas e em todas as coisas estava contida a água ${ }^{1}$. De forma análoga ao trabalho concreto, a água se plasma como uma categoria decisiva para os seres humanos; ela transcende sua forma fenomênica e particular, revelando sua substancialidade universal. A água está presente em todas as coisas e constitui-se como princípio inexorável de reprodução da existência da vida orgânica e da vida dos seres humanos.

Isso implica que a água, a terra e os seres humanos não vieram ao mundo para ser objetos de troca e servir como mercadoria, uma vez que não possuem em sua substância corpórea qualquer átomo imanente de subordinação teleológica aos preceitos inexoráveis dos capitalistas por mais lucro, como sinônimo da mais-valia apropriada do trabalhador. A água tem valor de uso em si mesma, assim como a terra, o ar e os bens naturais, pois independe da intervenção consciente dos homens para poder emergir. No entanto, numa determinada forma de sociabilidade, todas as coisas são transformadas em mercadoria, e a água doce acaba sendo enredada nas malhas do capital.

Com base na dialética crítica de Marx, o presente artigo apresenta a água nos limites do capital como mercadoria, bem como o processo de privatização da maior empresa estatal de Alagoas no tocante à mercantilização da água doce e saneamento básico na América Latina e como seu processo de privatização se inscreve no aprofundamento da dependência da periferia do capitalismo aos imperativos das grandes corporações transnacionais. A aquisição da Casal (Companhia de Saneamento de Alagoas), em setembro de 2020, pela multinacional canadense BRK Ambiental Participações S.A., representou a ampliação da entrega das riquezas naturais da América Latina ao capital estrangeiro em conluio com o "capital nacional", resultando, portanto, na intensificação das taxas de espoliação de suas riquezas hídricas e no aumento da exploração da força de trabalho dos sujeitos destituídos dos meios de produção e meios de subsistência.

\section{A transformação da água em mercadoria}

Após existir nos intermúndios dos modos de produção precedentes, buscando tirar proveito de relações de produção que não controlava diretamente e mediando extremos que fugiam a seu completo controle, o capital ergueu-se como força avassaladora capaz de submeter tudo a seus preceitos. Desta forma, o capital operou ontologicamente suas metamorfoses de capital usuário, mercantil ou comercial para capital industrial e financeiro.

O poder do capital sobre os seres humanos e a transformação dos seres humanos em apêndices de seus interesses não nasceram imediatamente de um tiro de pistola, mas careceram de mediações complexas para forjar-se lentamente no processo de acumulação primitiva de capitais que assegurou a industrialização das economias colonizadoras e a constituição do mais poderoso mecanismo de apropriação de mais-valia forjado na história da humanidade.

O saque e a pilhagem de riqueza dos povos colonizados e conquistados mediante mecanismos coercitivos possibilitou que o capital passasse da subordinação formal à subordinação real da força de trabalho mediante um desenvolvimento desigual e combinado. O desenvolvimento das economias colonizadoras inscreveu-se sob o entrave das forças produtivas nas nações colonizadas.

O controle do trabalho pelo capital, efetivado pela Revolução Industrial, possibilitou à teoria marxiana desvendar as categorias econômicas decisivas que regem a sociedade capitalista. Esse movimento elucidativo encontrou seu ponto áureo em $O$ capital, opus magnum publicado pela primeira vez em 1867, em que Karl Marx desvela a anatomia do modo de produção capitalista pela decodificação do fetichismo da mercadoria, do fetichismo da técnica, do fetichismo do dinheiro e do fetichismo do capital (mercantil, industrial e financeiro/ fictício) (MARX, 2013).

Marx (2013, p. 97) começa sua obra fundamental, $O$ capital, afirmando que "A riqueza das sociedades onde reina o modo de produção capitalista aparece como uma enorme coleção de mercadorias". A riqueza na 
sociedade capitalista ganha foro privilegiado na forma da mercadoria, porque esta se configura como a espécie mais plástica de manifestação da riqueza, transcendendo as formas precedentes, como a terra, a quantidade de escravos e servos etc.

A elucidação da natureza duplicada do trabalho que sustenta o mundo da mercadoria evidencia que subsiste uma forma de trabalho que se plasma como espécie de necessidade eterna dos homens, e outra forma específica de trabalho que serve de base ao modo de produção capitalista. O trabalho abstrato ou o tempo de trabalho socialmente necessário enquanto fundamento da relação de troca entre as mercadorias é a essência da teoria do valor. O trabalho abstrato oblitera literalmente as qualidades particulares desenvolvidas pelos trabalhadores.

Escreve Marx (2013, p. 98-99): “Com o caráter útil dos produtos do trabalho desaparece o caráter útil dos trabalhos neles representados e, portanto, também as diferentes formas concretas desses trabalhos que não mais se distinguem uns dos outros, são reduzidas a trabalho humano igual, a trabalho humano abstrato". O trabalho concreto desaparece no interior do trabalho abstrato, existindo somente vestígios do trabalho concreto realizado pelos trabalhadores. Portanto, "é apenas a quantidade de trabalho socialmente necessário ou o tempo de trabalho socialmente necessário para a produção de um valor de uso que determina a grandeza de seu valor" (MARX, 2013, p. 100).

A produção de coisas como mercadorias implica a produção visando diretamente à troca e não para atender às necessidades de seus produtores. Anota Marx (2013, p. 101): "Para se tornar mercadoria, é preciso que o produto, por meio da troca, seja transferido a outrem, a quem vai servir como valor de uso". As coisas, para se consubstanciarem em mercadoria, precisam não somente ser úteis, mas ser suportes de valor; para isso, resultam de uma relação social assentada no trabalho abstrato.

A necessidade de converterem-se no cristal monetário faz com que as distintas mercadorias não encontrem paz enquanto não experimentarem a metamorfose da mercadoria-dinheiro. Cada metamorfose do trabalho abstrato em mercadoria se constitui também na necessidade da metamorfose da mercadoria em dinheiro e do dinheiro em capital. Na investigação da particularidade da natureza duplicada da mercadoria como valor de uso e valor de troca, Marx (2013, p. 100-101, grifo nosso) observa ainda que

Uma coisa pode ser valor de uso sem ser valor. É esse o caso quando sua utilidade para o homem não é mediada pelo trabalho. Assim é o ar, a terra virgem, os campos naturais, a madeira bruta etc. Uma coisa pode ser útil e produto do trabalho humano sem ser mercadoria. Quem, por meio de seu produto, satisfaz sua própria necessidade, cria certamente valor de uso, mas não mercadoria. Para produzir mercadoria, ele tem de produzir não apenas valor de uso, mas valor de uso para outrem, valor de uso social.

Nota-se que existem coisas na natureza que têm valor de uso para os seres humanos e não têm valor de troca porque não possuem nenhum quantum de trabalho em seu interior. Além disso, há coisas que possuem valor de uso e não têm valor de troca porque não derivam de relações de produção assentadas na produção de mercadorias. As relações de produção e os modos de produção que precederam o capitalismo e a hegemonia do capital sobre os seres humanos não estavam organizadas para produzir valor de troca; as coisas tinham somente valor de uso, ou seja, eram produzidas para atender às necessidades diretas de seus produtores, existindo as trocas somente episodicamente nas fronteiras dessas sociedades com outras sociedades.

O valor de uso é elemento essencial do trabalho concreto, enquanto o trabalho abstrato não passa de um acessório para a produção do valor de troca. No entanto, existem coisas que têm utilidade sem portar em seu interior a presença de qualquer modalidade de trabalho, seja trabalho concreto (relação do homem com a natureza) ou trabalho abstrato (forma de produção capitalista).

No processo de constituição do ser social, a terra e a água preexistem de maneira independente da vontade humana, pois a natureza independe da presença humana e torna-se base essencial do trabalho. Este encontra na natureza os elementos fundamentais para a produção de matéria-prima. As coisas existentes em seu estado natural possuem utilidade sem se constituírem como produto do trabalho humano e muito menos valor de troca, como é caso da água doce. Escreve Marx (2013, p. 188):

Todas as coisas que o trabalho apenas separa de sua conexão imediata com a totalidade da terra são, por natureza, objetos de trabalho preexistentes. Assim é o peixe, quando pescado e separado da água, seu elemento vital, ou a madeira que se derruba na floresta virgem, ou o minério arrancado de seus veios. [...] 
Toda matéria-prima é objeto do trabalho, mas nem todo objeto do trabalho é matéria-prima. O objeto de trabalho só é matéria-prima quando já sofreu uma modificação mediada pelo trabalho.

A água potável em si possui uma utilidade essencial à reprodução da vida e dos seres humanos sem conter nenhuma quantidade de trabalho. No entanto, o desenvolvimento das relações sociais requer o afastamento das barreiras naturais e a ampliação das necessidades humanas e, consequentemente, a necessidade de a água ser deslocada de suas reservas e fontes naturais para chegar até os seres humanos. Embora a água doce independa da vontade humana para subsistir, o desenvolvimento das relações sociais e das relações de produção demanda certa racionalidade para que os mananciais de água sejam preservados e suas reservas não se esgotem.

A constituição das distintas vias de acesso do homem à água implica a presença de trabalho humano, logo a água deixa de ser um simples valor de uso dado pela natureza para carecer também da mediação do trabalho humano. Serve não somente para o consumo humano, mas também como matéria-prima para o desenvolvimento e funcionamento dos meios de produção, a exemplo de engenhos, indústrias, hidroelétricas etc. Na sociedade capitalista, a presença do trabalho abstrato em qualquer coisa faz dela portadora de um valor e, consequentemente, sujeita à troca e à sua transformação em mercadoria-dinheiro.

A constituição de múltiplos mecanismos de acesso à água potável para o consumo humano e para servir como matéria-prima da manufatura ou agricultura não se forjou como criação específica do modo de produção capitalista. As distintas sociedades asiáticas ou tributárias operaram processos complexos de beneficiamento da água, sistemas hidráulicos, sistemas de irrigação, canalização, drenagem etc. para atender às necessidades humanas na condição exclusiva de valor de uso. As redes de saneamento e a canalização de água precederam o modo de produção capitalista e existiram nas sociedades da América Latina (incas, astecas, maias, olmecas, toltecas etc.) antes da chegada dos colonizadores europeus, sendo completamente desmanteladas pela ação do capital.

A particularidade do modo de produção capitalista consiste na transformação da água em mercadoria. As vicissitudes do desenvolvimento da produção capitalista ensejam a necessidade do desenvolvimento das forças produtivas, o que exige a constituição de um sistema em que a água doce acaba sendo despertada de sua natureza em si para atender aos interesses do mercado. Assim, o capital lança mão das forças adormecidas na natureza e aproveita a capacidade hidráulica para fazer um moinho de água para a instalação de um engenho ou para a construção de uma hidroelétrica, que produz energia não somente na perspectiva de assegurar o funcionamento de suas caldeiras, turbinas, motores, máquinas, instrumentos e utensílios, mas prioritariamente visando à produção do lucro.

Como um moinho e uma hidroelétrica presumem o trabalho abstrato, a água nas mãos dos capitalistas passa a possuir tanto valor de uso quanto valor de troca, mesmo que isso seja realizado pela mediação do Estado e não diretamente por um capitalista como o Barão de Mauá ou Delmiro Gouveia, pois as taxas cobradas pelos recursos hídricos oferecidos são determinadas pelo tempo de trabalho socialmente necessário.

A constituição da sociedade de classes implica sempre a necessidade de apropriação do excedente produzido pelos trabalhadores. No modo de produção asiático existente na América Latina antes da chegada dos colonizadores, o Estado constituía grandes sistemas de irrigação, sistemas de drenagem, canalização de água potável, construção de pontes e estradas com o excedente apropriado dos camponeses. Uma parte do excedente apropriado na forma de tributos retornava aos camponeses na forma de serviços à comunidade. A guerra ao modo de produção comunal e ao modo de produção asiático ou tributário existente na América Latina foi um pressuposto essencial da colonização capitalista. Neste processo, a terra paulatinamente se transformou em mercadoria e a água num elemento fundamental para elevar seu valor de troca.

O valor da terra, como as demais mercadorias, é determinado pelo tempo de trabalho socialmente necessário, ou seja, pelos investimentos realizados pela mediação do trabalho abstrato e pela capacidade produtiva da terra segundo os preceitos capitalistas. A existência de água doce num solo, por exemplo, denota que este tem maior potencialidade produtiva do que um pedaço de solo destituído do precioso elemento. Marx (2013) demonstra isso de forma detalhada no livro terceiro de $O$ Capital, quando trata da renda da terra e das distinções existentes entre renda da terra, renda diferencial I e II, renda absoluta e renda de monopólio.

A renda da terra, enquanto parte da mais-valia apropriada pela burguesia agrária e repassada para o proprietário da terra (arrendatário), é o resultado da diferença estabelecida da mesma quantidade de capital e trabalho empregado numa mesma quantidade de terra. A existência de água numa determinada terra bem 
como seu nível de fertilidade, localização e distribuição a tornam mais rentável para o capitalista do que uma terra destituída desses elementos adicionais.

A existência de uma queda d'água num terreno torna-o mais valorizado porque permite um lucro extraordinário à proporção que permite a instalação de um moinho e a utilização de sua força hidráulica, poupando força de trabalho. Permite assim a redução dos custos de produção e possibilita o sobrelucro ao seu proprietário. Embora a queda d'água não resulte do trabalho humano, ela torna o trabalho humano mais produtivo; da mesma forma, a terra fértil não é produto do trabalho, mas torna o trabalho na terra mais produtivo, barateando os custos de produção. Embora a queda d'água não produza mais-valia, ela possibilita que o proprietário da terra atraia o sobrelucro para o seu bolso (MARX, 1984).

Expropriados dos meios de produção e dos meios de subsistência, os trabalhadores (indígenas, ex-escravos e camponeses) foram lançados nas grandes cidades para vender sua força de trabalho em condições análogas à escravidão. O serviço de abastecimento de água nas cidades somente foi alterado na América Latina no decorrer da segunda metade do século XX, quando o Estado assumiu um papel essencial na venda do serviço de abastecimento de água e saneamento básico, cobrando taxas aos usuários para cobrir as despesas com os custos de captação, tratamento e distribuição da água.

A luta dos trabalhadores pela elevação do valor de sua força de trabalho obriga o Estado a investir na prestação do serviço de água encanada e no saneamento básico, primeiramente nos grandes centros urbanos industrializados, em que a água vai deixando de ser entregue em carroças e carros de mão por vendedores ambulantes e passando a ser canalizada. Isso é possibilitado pelo excedente apropriado dos trabalhadores (tributos, taxas, impostos etc.) pelo Estado, que passa a investir especialmente nos bairros da burguesia. Não é à toa que até hoje os trabalhadores da periferia do tecido urbano e rural da América Latina continuam sem usufruir desse serviço.

O próprio Estado colaborou para transformar a água e o saneamento básico em mercadorias, já que justificava a cobrança de taxas aos usuários pelos investimentos realizados e pelas despesas com o tratamento da água, tubulação, armazenamento, distribuição etc. A diferença em relação aos tempos hodiernos é que a cobrança de taxas não era completamente regida pelo preceito do lucro incomensurável e pela noção da água como uma espécie de commodity negociada na Bolsa de Valores como mercadoria. O fornecimento de água potável e a constituição do sistema de saneamento básico e esgoto assumiram uma nova configuração com a crise estrutural do sistema do capital a partir da década de 1970. É que a mais-valia capitalizada carecia de novos espaços para investimento e não se podia retornar à produção assegurando sua reprodução ampliada.

\section{A privatização da Casal no contexto da mercantilização da água na América Latina}

A crise econômica experimentada na década de 1970 resultou no fim do acordo de Breton Woods e na hipertrofia do capital financeiro. O excesso de capitais emanados da produção petrolífera serviu para que Wall Street subordinasse completamente as economias dependentes mediante a intensificação da dívida pública. A impossibilidade de a mais-valia capitalizada retornar à produção de forma ampliada, devido ao enxugamento dos mercados propiciado pela recuperação econômica europeia e japonesa, impôs a necessidade de o capital monopolista expandir-se para a esfera dos serviços prestados pelo Estado que se constituíam como direitos essenciais dos trabalhadores.

A privatização dos serviços públicos de educação, previdência social e saúde estendeu-se também para os setores estratégicos e essenciais das economias na periferia do capitalismo (como na América Latina). Entre esses setores destaca-se o processo de privatização dos transportes públicos (ferrovias, rodovias, sistema portuário e aeroportos), das reservas e sistemas de fornecimento de água potável e da complexa rede de energia elétrica (hidroelétricas, estações de transmissões etc.). Nesse processo, os direitos dos trabalhadores e os bens da sociedade são privatizados para atender às exigências de expansão e acumulação de capitais, reciclando e atualizando o processo de acumulação primitiva de capitais, como na época da colonização².

Com o auxílio das agências de fomento imperialistas - Banco Mundial e Fundo Monetário Internacional (FMI) - , forjou-se o Conselho Mundial da Água, que constituiu a política fundamental para entregar os mananciais de água doce em várias partes do mundo a corporações multinacionais como Veolia (antiga Vivendi Universal, presente em mais de noventa países), Suez (antiga Lyonaise des Eaux, presente em mais de 130 
países), Bouygues-SAUR, RWE-Thames Water, Bechtel-United Utilities, Servern Trent, Anglian Water, Kelda Group, Dow Chemicals. Não se trata simplesmente de um processo de mercantilização da água engarrafada no mercado mundial, mas da mercantilização das reservas de água do planeta, bem como de todo o processo de captação, tratamento, distribuição e envasamento. Dessa maneira, constituiu-se um mercado promissor de água nas distintas partes do mundo:

[...], mercados de neve desenvolvidos na costa semiárida a leste da Espanha (MALLOL FERRÁNDIZ, 1989), os mercados de irrigação por água subterrânea nas Ilhas Canárias (AGUILERA KLINK, 2002; MACÍAS HERNÁNDEZ, 1990), Índia, Bangladesh ou Paquistão (MEINZEN-DICK, 2000; SADEQUE, 2000), ou os chamados mercados "maduros" ou "estabelecidos" de água na região sul da Austrália, Chile ou partes dos Estados Unidos [...] (CASTRO, 2016, p. 360-361).

As corporações passaram a controlar aproximadamente $70 \%$ da água privatizada do planeta; a Suez e a Veolia chegaram ao controle de $50 \%$ do mercado mundial. No Brasil, a Suez se apropriou do processo de abastecimento de água e saneamento em cidades como Manaus, Campo Grande, Brasília e Limeira, e passou a exercer o controle acionário de nove empresas do setor em 2016 (IRIGARAY, 2016, p. 57).

O processo de mercantilização acirrou as contradições pelo acesso à água, transcendendo as disputas circunscritas às regiões desérticas e com problemas climáticos, como os desertos do Saara, do Oriente Médio ou do semiárido do Nordeste brasileiro, e invadiu o cotidiano da classe trabalhadora da América Latina. Esse processo de mercantilização contou com a resistência dos trabalhadores latino-americanos. A região de Tucumán (Argentina), por exemplo, conseguiu impor uma derrota expressiva a uma filial da Veolia em 1997, mediante a recusa organizada da população em pagar pelas tarifas abusivas cobradas e pelo processo de deterioração da qualidade da água e do serviço prestado (IRIGARAY, 2016).

Em 2006, o governo de Néstor Kirchner rompeu contrato com a multinacional francesa Suez (Águas Argentinas), pelo descumprimento dos acordos estabelecidos na prestação do serviço de água e esgoto na Grande Buenos Aires, reestatizando os serviços prestados. Inconformados, os representantes da corporação transnacional entraram com ação no tribunal de arbítrio do Banco Mundial cobrando ao governo argentino o ressarcimento da soma astronômica de 1,7 bilhão de dólares de indenização (MARREIRO, 2006, p. 1).

Situação análoga foi observada na denominada Guerra da Água de Cochabamba, na Bolívia, em que os trabalhadores organizados conseguiram impedir que o sistema de água da cidade passasse das mãos da prefeitura para o controle do grupo norte-americano Bechtel. Nem mesmo a pressão do Banco Mundial, em 2000, na perspectiva de não renovar os empréstimos de 25 milhões de dólares à Bolívia, conseguiu impedir o sucesso do movimento popular (IRIGARAY, 2016).

Inúmeros outros protestos obstaram a atuação predatória dessas multinacionais na América Latina. No Alto Lima (Peru), os boicotes sistemáticos e organizados dos moradores levaram o executivo da Lyonnaise, Arnaud Bazire, a afirmar que "a população do Alto era 'o pior cliente' e 'o pior consumidor do mundo"” (POUPEAU, 2002, p. 2). No México, os trabalhadores se contrapuseram aos interesses mercantilistas da Coca-Cola, empresa beneficiada num processo de privatização que suspendeu o completo abastecimento de água em cinco vilas (IRIGARAY, 2016, p. 58).

As medidas neoliberais adotadas pelos governos de Margareth Thatcher, Ronald Reagan e Augusto Pinochet universalizaram o processo de transformação da água doce em mercadoria, que se converteu em atividade lucrativa das grandes corporações transnacionais. As pressões realizadas pelo Banco Mundial e pelo FMI visando desmantelar as estruturas de fornecimento de água potável às populações urbanas nos momentos de negociação e renegociação da dívida pública transformaram os Estados em aliados fundamentais da privatização das companhias estatais de água. Os "Programas de Ajuste Estrutural” impostos pelo FMI, pelo Banco Mundial e consortes aprofundaram a dependência econômica latino-americana e, particularmente, das economias situadas na periferia da periferia do capitalismo, como a economia alagoana (IRIGARAY, 2016).

Para justificar a necessidade de privatização, os governos de plantão da burguesia na América Latina ressaltaram a inexistência de recursos para investir no saneamento básico. No Brasil, esses preceitos foram claramente estabelecidos pelo novo marco do saneamento básico, em que as empresas privadas do setor poderão crescer expressivamente nos próximos anos com respaldo nas leis aprovadas pelo Congresso Nacional (Lei n. 4.162/2019) (BRASIL, 2019). Na verdade, a abertura para a entrada de multinacionais estrangeiras na ampliação 
da malha de infraestrutura de saneamento não passa de um ardil para entregar completamente o sistema público de distribuição e exploração dos mananciais de água doce que abastecem os municípios brasileiros ${ }^{3}$.

Além da Lei n. 4.162/2019, existe o Projeto de Lei n. 495/2017, que aprofunda o processo de mercantilização da água doce no Brasil. O preço da água potável será vinculado ao preço da energia elétrica, de forma que os trabalhadores precisarão desembolsar um maior valor para consumir água potável. É como se ao beber água o consumidor estivesse bebendo eletricidade (CALISTO; ALVES, 2020). A nova lei determina que a Agência Nacional das Águas (ANA) seja a única responsável pela regulamentação mercadológica da prestação dos serviços de saneamento básico e do fornecimento de água potável no Brasil. Assim, os municípios e as organizações dos trabalhadores perderão o controle do fornecimento de água e saneamento básico, uma vez que a referida agência é regida pelos preceitos do mercado (CALISTO; ALVES, 2020).

O PL n. 495/2017 defende ainda que as bacias brasileiras sejam controladas pelo mercado de água. Com essa medida a bacia do rio São Francisco e todo o processo de transposição culminaram sendo controlados por grupos transnacionais como Ambev, Vale, Veolia, Suez, Coca-Cola, Nestlé, Danone, Raizen, BTG Banco Pactual, Itaú, AEGEA, BRK Ambiental Participações S.A., Grupo Águas do Brasil, GS, Bechtel e consortes (CALISTO; ALVES, 2020). Desse modo, todas as reservas e fontes de água potável existentes no território brasileiro devem ser transformadas em mercadoria e comercializadas da mesma forma que a energia elétrica.

A privatização da Companhia de Saneamento Básico de Alagoas (Casal) deu-se no interior do processo de privatização da água no continente que possui as maiores reservas de água potável do mundo. O Aquífero Guarani (Argentina, Brasil, Paraguai e Uruguai) e o Aquífero Alter do Chão (que representa 15\% da água doce depositada nos oceanos anualmente) representam os maiores aquíferos do planeta (IRIGARAY, 2016). Isso torna a América Latina o endereço principal dos processos macroeconômicos de privatização e mercantilização. O elevado potencial hídrico converte-a na região mais cobiçada pelas corporações transnacionais. Nela ocorreram as primeiras experiências de privatização da água nas economias periféricas.

Num contexto de um país que possui $13 \%$ da água doce do planeta, o governo de Alagoas operacionaliza o processo de entrega da Casal, maior empresa pública do estado, para a multinacional Equatorial (canadense BRK Ambiental Participações S.A.) (CASAL, 2020, p. 1). Para dobrar a resistência interna do movimento dos trabalhadores organizados, o governo Renan Filho (MDB) introduziu o debate da privatização separando o fornecimento e tratamento de água da parte relativa ao serviço de esgotos da companhia.

A necessidade de inserção do capital privado no setor de saneamento básico foi ardilosamente justificada pela afirmação da inexistência de recursos públicos para atender às demandas existentes. A incapacidade do estado de Alagoas para investir no fortalecimento da rede de saneamento básico de Maceió e de seus 102 municípios abriu as portas para o discurso privatista que interessava à burguesia nacional e internacional.

O novo marco regulatório do saneamento básico viabilizou a adoção das medidas neoliberais em plena época de pandemia do coronavírus. A privatização sacraliza a noção de que o serviço de saneamento básico e o fornecimento de água doce deixam de ser uma obrigação estatal e um direito dos trabalhadores e se transformam em mercadoria, desconsiderando-se completamente o preceito constitucional que assegura o saneamento como elemento indispensável e essencial à saúde pública.

A referida privatização ocorreu no contexto de desresponsabilização do Estado para com os direitos essenciais dos trabalhadores e trabalhadoras, conforme reza a Constituição Federal (artigo 23, incisos II e IX): “Art. 23. É competência comum da União, dos Estados, do Distrito Federal e dos Municípios: [...] IX promover programas de construção de moradias e a melhoria das condições habitacionais e de saneamento básico" (BRASIL, 1988).

Em vez de serem os responsáveis pela prestação de serviços públicos de qualidade, os governos da burguesia na América Latina desresponsabilizam o Estado para com a saúde e o saneamento básico, de modo que ele deixa de realizar os investimentos necessários e fundamentais para garantir uma vida saudável no espaço urbano e rural. A ausência de investimentos em saneamento básico resulta no adoecimento da população, especialmente dos trabalhadores que moram na periferia das cidades. Assim, os esgotos expostos e a fedentina fazem parte da paisagem grotesca de bairros como Vergel do Lago, Dique Estrada, Brejal e muitos outros.

Evidentemente, empresas transnacionais não irão operacionalizar investimentos em bairros populares habitados sobremodo pelo exército industrial de reserva, em que os seres humanos são figuras supérfluas ao processo de reprodução do sistema do capital. As transnacionais estão exclusivamente interessadas no lucro e não na promoção de uma vida digna para os trabalhadores, muito menos na constituição de uma rede de 
saneamento básico que vise prevenir doenças, epidemias e pandemias. A venda da Casal tem como elemento central a mercantilização com o abastecimento de água e representa o desmantelamento dos serviços públicos.

Indiferente à responsabilidade pública para com a prestação do serviço de saneamento básico e o fornecimento de água potável, o governo Renan Filho privatizou a parte mais eficiente e lucrativa da Casal em 30 de setembro de 2020, entregando para a BRK Ambiental Participações S.A. o controle absoluto do abastecimento de água e saneamento de 13 municípios que compõem a região Metropolitana, a saber: Atalaia, Barra de Santo Antônio, Barra de São Miguel, Coqueiro Seco, Maceió, Marechal Deodoro, Messias, Murici, Paripueira, Pilar, Rio Largo, Santa Luzia do Norte e Satuba.

A multinacional BRK Ambiental Participações S.A. adquiriu a maior empresa pública do estado pelo irrisório valor de 2 bilhões de reais, com direito de explorar os consumidores de água e o esgotamento sanitário da região mais estruturada do estado de Alagoas. Segundo a Agência Alagoas (CARVALHO; ALMEIDA, 2020, p. 1):

A BRK assumirá a concessão dos serviços de água e esgoto de 13 cidades da Região Metropolitana de Maceió, que reúnem 1,5 milhão de habitantes. Após apresentar a proposta de maior outorga fixa ao Estado, com o valor de $\mathrm{R} \$ 2$ bilhões, a empresa assina um contrato de 35 anos e será responsável por investir R \$2,6 bilhões em infraestrutura ao longo do período de concessão, sendo R $\$ 2$ bilhões já nos seis primeiros anos.

A referida empresa é uma das maiores corporações privadas de saneamento do Brasil, com monopólio da distribuição de água em mais de 186 municípios. BRK é a abreviação da multinacional canadense Brookfield Asset Management, que detém 70\% das ações ordinárias da BKF do Brasil; a outra parte, contraditoriamente, pertence ao Fundo de Investimento do Fundo de Garantia do Tempo de Serviço do Trabalhador (FI-FGTS), com mediação do BNDES (CARVALHO; ALMEIDA, 2020, p. 1; MELLO, 2020, p. 1)). Isso significa que os recursos dos trabalhadores são drenados para o sistema financeiro e contra os próprios trabalhadores que o constituíram.

A mediação do BNDES no processo de privatização da Casal está plenamente conectada ao fato de que o referido banco de desenvolvimento utiliza os recursos dos trabalhadores para financiar as ações dos capitalistas em distintos setores, inclusive no processo de privatização que se contrapõe radicalmente aos interesses dos trabalhadores.

A BRK Ambiental Participações deriva da Odebrecht Ambiental e foi criada em 2008. A afiliada da Odebrecht exerceu papel pioneiro no campo da privatização do saneamento básico e da água no território brasileiro até 2016, quando foi vendida para a Brookfield Asset Management (BROOKFIELD, 2020)4. Por sua vez, o investimento do BNDES, pela mediação do FI-FGTS, permaneceu e constitui um mecanismo de capitalização para fortalecer a iniciativa privada com recursos dos trabalhadores.

$\mathrm{Na}$ batalha pelo processo de privatização, não se pode deixar de conceder mérito a quem precisa de mérito. Os capitalistas devem realmente render tributo ao governador Renan Filho e seus asseclas (assessores, secretários e conselheiros), e especialmente prestar homenagem ao desembargador Tutmés Airan, presidente do Tribunal de Justiça de Alagoas (TJ/AL), que atendeu pedido de suspensão da decisão da desembargadora Elisabeth Carvalho, que havia vetado, em caráter liminar, ou seja, provisório, o leilão da Companhia de Saneamento de Alagoas (Casal) marcado para acontecer no dia 30 de setembro de 2020, na sede da Bolsa de Valores de São Paulo. O pedido foi feito pela Procuradoria Geral do Estado (PGE). Com a nova decisão judicial, o leilão da Companhia de Saneamento foi mantido (BARROS, 2020).

Em suas alegações, o desembargador afirma que a ausência de um leilão objetivando a privatização da Companhia provocaria grave lesão à economia pública, já que o processo licitatório abrangia investimentos na ordem de $\mathrm{R} \$ 2,6$ bilhões, a serem empregados em obras de abastecimento de água e esgotamento sanitário em todos os 13 municípios da Grande Maceió. Tutmés Airan argumentou falaciosa e inveridicamente que a suspensão do leilão promoveria o colapso do sistema e que não existiria saída para a continuidade do sistema de abastecimento fora da privatização (BARROS, 2020).

Longe de investigar os indícios de irregularidade do processo de privatização apontados pela desembargadora Elisabeth Carvalho, Tutmés Airan se curvou ao poder das transnacionais quando derrubou a liminar que impedia o leilão, e escancarou seu pacto mefistofélico com a multinacional canadense. Na luta entre capital e trabalho, a Justiça claramente colocou-se ao lado do capital e contra os trabalhadores. 
A privatização afetará diretamente os trabalhadores da Casal e do Serviço Autônomo de Água e Esgoto (SAAE), levando à demissão de 720 trabalhadores da Casal e de milhares de trabalhadores do SAAE (CARVALHO, 2020, p. 2). Para barrar o processo, os trabalhadores realizaram diversos protestos públicos, inclusive o fechamento da BR-101 Sul/Alagoas, bem como entraram com recurso exigindo o cancelamento do leilão em que a empresa foi vendida. Dentre outras irregularidades, o representante do SAAE destacou:

[...] a Lei Complementar Estadual no 50, de 15 de outubro de 2019, que dispõe sobre o sistema gestor da Região Metropolitana de Maceió, seria inconstitucional por ferir o pacto federativo, sobretudo no que se refere à autonomia municipal. Argumenta, ainda, que o processo licitatório previsto na Concorrência Pública no 09/2020 CASAL/ALCEL/RMM seria "eivado de nulidades, uma vez que não teriam sido realizadas audiências públicas em todos os municípios afetados, bem como e, principalmente, pelo fato de que a concessão seria restrita às áreas urbanas, deixando a zona rural para ser atendida pelo SAAE" (CARVALHO, 2020, p. 2).

O governo do estado, com total respaldo de Tutmés Airan (Poder Judiciário), entregou uma empresa que não lhe pertencia. Patrimônio da sociedade alagoana, uma parte da empresa pertencia aos municípios; a maioria contrapunha-se à privatização da empresa. Os municípios asseguravam o funcionamento do sistema de abastecimento de água e o saneamento básico com milhares de funcionários atuando no setor.

A privatização do sistema de saneamento e abastecimento de água na região metropolitana não dependia exclusivamente do governo estadual, pois contava com a participação das prefeituras e dos trabalhadores; estes foram completamente desrespeitados e por isso entraram com ação no Supremo Tribunal Federal alegando a inconstitucionalidade da privatização, que dificilmente será revogada.

Devido às pressões populares contra a privatização, a Casal permanecerá efetuando a captação e o tratamento da água e repassará o precioso líquido para a concessionária privada; já a Brookfield Asset Management explorará em bases lucrativas os serviços de distribuição de água e todos os serviços de esgotamento sanitário (coleta e tratamento dos esgotos), bem como a parte comercial (cobrança e arrecadação). As tarifas dos serviços de água e saneamento deverão manter-se bem acima da inflação nos próximos trinta anos.

\section{Considerações Finais}

A presença da multinacional canadense deverá, ao contrário do que afirma Tutmés Airan, aprofundar as contradições (doenças, miséria e pauperismo) no interior da classe trabalhadora, com a constituição de um espaço urbano cada vez mais insalubre e doentio. Ao isentar-se completamente da responsabilidade com o saneamento básico e com o sistema de abastecimento de água, o Estado concede as bases para que as corporações ampliem suas taxas de lucro, sugando ainda mais o sangue dos trabalhadores e trabalhadores da periferia do capitalismo. A privatização aprofundará as contradições iniciadas com a adoção das medidas neoliberais na década de 1990.

A privatização da Casal faz parte de uma política coordenada de entrega das riquezas hídricas da América Latina aos representantes do grande capital. De maneira análoga à Ceal, ao porto de Maceió, às plantas da Petrobras em Pilar e São Miguel dos Campos, as grandes estatais situadas em Alagoas foram privatizadas para atender aos imperativos da expansão e acumulação de capitais. Enquanto determinadas potências mundiais (EUA, China, Alemanha, Canadá etc.) constatam a necessidade de reestatizar as empresas de água e saneamento, dada a sua relevância estratégica para a soberania e a segurança nacional (CENTRO EXPERIMENTAL DE SANEAMENTO AMBIENTAL, 2020, p. 1), as economias dependentes da América Latina as privatizam e aprofundam sua dependência das economias centrais. Isso implica que as taxas de pobreza e miséria devem aumentar na América Latina, pois as taxas de violência social, desemprego e pauperismo ampliaram-se expressivamente desde que começaram as aplicações das medidas neoliberais recomendadas pelo Banco Mundial e pelo FMI.

Nesse cenário, a privatização da água vai servir para acentuar o aprofundamento das desigualdades sociais e o crescimento da miséria da classe trabalhadora, pois os capitalistas não pretendem recuar em sua ânsia para expropriar as riquezas naturais da América Latina mediante o saque, a espoliação e o roubo das riquezas produzidas pelos trabalhadores. A privatização dos mananciais de água acentuará ainda mais o processo 
de expropriação das riquezas naturais pertencentes às comunidades indígenas, ribeirinhas, quilombolas e camponesas.

Por isso é essencial organizar a resistência, como fizeram os trabalhadores da Cochabamba (Bolívia), Tucumán (Argentina) e do Alto Lima (Peru). É fundamental formar polos de resistência para dizer "não" à privatização da água na América Latina, pois a água é um valor de uso que pertence à humanidade e não aos capitalistas e suas gigantescas corporações. Enquanto elemento essencial para assegurar a reprodução da humanidade e garantir a qualidade de vida, a água precisa ser cuidada. Portanto, fazem-se necessários instrumentos que superem o trabalho abstrato e assegurem a realização de uma forma de organização da produção assentada no trabalho associado, livre e universal.

\section{Referências}

BARROS, J. Presidente do TJ/AL suspende liminar, e leilão da Casal está mantido. Gazeta Web, Alagoas, 30 set. 2020. Disponível em: https://gazetaweb.globo.com/portal/noticia/2020/09/_116109.php. Acesso em: 22 dez. 2020.

BRASIL. [Constituição (1988)]. Constituição da República Federativa do Brasil de 1988. Brasília, DF: Presidência da República. Centro Gráfico, 1988.

BRASIL. Congresso Nacional. Projeto de Lei no 4.162 de 2019. Atualiza o marco legal do saneamento básico e altera a Lei $n^{\circ} 9.984$, de 17 de julho de 2000, para atribuir à Agência Nacional de Águas competência para editar normas de referência sobre o serviço de saneamento. Disponível em: https://www.camara.leg.br/proposicoesWeb/fichadetramitacao?idProposicao=2235973. Acesso em: 22 dez. 2020.

BROOKFIELD. Presença global. Disponível em: https://www.brookfield.com/pt-br/sobre-nos/presenca-global. Acesso em: 12 jan. 2020.

CALISTO, D.; ALVES, J. J. O avanço da estratégia de privatização da água no Brasil. Brasil de Fato, São Paulo, 27 jun. 2020. Disponível em: https://www.brasildefato.com.br/2020/06/27/artigo-o-avanco-da-estrategia-de-privatizacao-da-agua-no-brasil. Acesso em: 24 dez. 2020.

CARVALHO, R. Prefeituras vão à justiça contra leilão da Casal. Gazeta de Alagoas, Maceió, 2 dez. 2020. Disponível em: https://d. gazetadealagoas.com.br/politica/283015/prefeituras-vao-a-justica-contra-leilao-da-casal. Acesso em: 22 dez. 2020.

CASAL. Esgoto sanitário. Disponível em: https://www.casal.al.gov.br/capital-2/. Acesso em: 22 de dez. de 2020.

CARVALHO, S.; ALMEIDA, A. C. Governo e BRK iniciam discussão sobre plano de transição dos serviços de água e esgoto. Agência Alagoas, Maceió, 20 out. 2020. Disponível em: http://www.agenciaalagoas.al.gov.br/noticia/item/34363-agua-e-esgoto-governo-ebrk-iniciam-discussao-sobre-plano-de-transicao-dos-servicos. Acesso em: 22 dez. 2020.

CASTRO, J. E. A água (ainda) não é uma mercadoria: aportes para o debate sobre a mercantilização da água. Revista da Universidade Federal de Minas Gerais, Belo Horizonte, v. 20, n. 2, p. 190-221, 2016. DOI: 10.35699/2316-770X.2013.2697. Disponível em: https:// periodicos.ufmg.br/index.php/revistadaufmg/article/view/2697. Acesso em: 13 maio 2021.

CENTRO EXPERIMENTAL DE SANEAMENTO AMBIENTAL. Brasil é vice-líder mundial em reestatização da água. Disponível em. http://www.saneamento.poli.ufrj.br/index.php/br/noticias/538-brasil-e-vice-lider-mundial-em-reestatizacao-da-agua. Acesso em: 24 de dez. de 2020.

HARVEY, D. O “novo” imperialismo: acumulação por espoliação. [São Paulo]: Socialist Register, 2004.

HEGEL, G. F. W. Tales de Mileto. Tradução de Ernildo Stein. In. Os Pré-socráticos. São Paulo. Abril Cultural, 1973.

IRIGARAY, M. C. Privatização e mercantilização da água na América latina: desafios da sustentabilidade e defesa do bem (de uso) comum "no" e "para além" do capitalismo. 2016. Dissertação (Mestrado em Pesquisa Direitos da Sociobiodiversidade e Sustentabilidade) - Universidade Federal de Santa Maria, Universidade Federal de Santa Maria, Rio Grande do Sul, 2016.

MARREIRO, F. Argentina reestatiza empresa de água e esgoto. Folha de São Paulo, São Paulo, 22 mar. 2006. Disponível em: https:// www1.folha.uol.com.br/fsp/dinheiro/fi2203200602.htm. Acesso em: 14 jan. 2021.

MARX, K. O Capital: Crítica da Economia Política. Livro III. Tradução de Regis Barbosa e Flavio R. Kothe. São Paulo: Abril Cultural, 1984.

MARX, K. O Capital: o processo de produção do capital. Livro I. Trad. Rubens Enderle. Sâo Paulo: Boitempo, 2013.

MELLO, Daniel. Empresa BKF Ambiental vence leilão de serviços de água em Maceió. Endereço eletrônico: https://agenciabrasil. ebc.com.br/economia/noticia/2020-09/empresa-bkr-ambiental-vence-leilao-de-servicos-de-agua-em-maceio. Acesso em 14 de janeiro de 2021.

POUPEAU, F. E a água foi privatizada.... Le Monde Diplomatique Brasil, [São Paulo], 1 maio 2002. Disponível em: https://diplomatique. org.br/e-a-agua-foi-privatizada/. Acesso em: 14 jan. 2021. 


\title{
Notas
}

1 A água como princípio universal é explicada por Georg W. F. Hegel (1973, p. 15) nos termos: "A proposição de Tales de que a água é o absoluto ou, como diziam os antigos, o princípio, é filosófica; com ela, a Filosofia começa, porque através dela chega à consciência de que o um é a essência, o verdadeiro, o único que é em si e por si”.

2 O processo de acumulação por espoliação se configura como elemento nodal no capitalismo contemporâneo. Harvey (2004) salienta ainda que emergiram novos mecanismos de acumulação por espoliação, como a ampliação do direito de propriedade intelectual, em que grandes corporações registram patentes e auferem lucros no campo da liberação de licença para uso de materiais genéticos. Essa forma de acumulação se estende ao processo de privatização de ativos públicos, como o conhecimento produzido pelas universidades, e ao processo de privatização dos recursos naturais e dos serviços públicos, que deveriam ser um bem comum (HARVEY, 2004, p. 110).

3 Segundo Calisto e Alves (2020, p. 1): "a nova lei, a partir de março de 2022, todos contratos de prestação de serviços de saneamento (o que inclui distribuição de água, coleta e tratamento de esgoto e resíduos) existentes entre os municípios brasileiros e as estatais de saneamento, em sua maioria, poderão ser revisados e reavaliados. Ao invés de continuarem a existir os contratos de programa, será obrigatório a realização de editais de licitação entre empresas públicas e privadas, que poderão acarretar, em menos de dois anos, na privatização da maioria dos serviços de saneamento no País. Isso significa que se antes a privatização era uma possibilidade dentro da legislação do saneamento, agora tornou-se quase que uma obrigação, no novo marco legal".

4 O portfólio da referida multinacional aponta a ampliação de suas atividades na América Latina (Brasil, Colômbia e Peru) pela mediação das expropriações representadas nas privatizações de empresas estatais nos termos: "Em 2017, adquirimos a BRK Ambiental, a maior operadora de sistemas de água e tratamento de esgoto do Brasil, que atende a aproximadamente 15 milhões de pessoas. Começamos as operações na Colômbia em 2011 com uma distribuidora elétrica e, em 2016, adquirimos a Isagen S.A., uma das maiores geradoras de energia da Colômbia. No mesmo ano, adquirimos uma participação de 57\% em Rutas de Lima, uma concessão rodoviária no Peru". (BROOKFIELD, 2020, p. 1).

\author{
Artur Bispo dos Santos Neto \\ artur.neto@ichca.ufal.br \\ Pós-doutorado em Filosofia pela Universidade Federal de São Paulo (UNIFESP) \\ Professor Associado III da Universidade Federal de Alagoas (UFAL)
}

\section{Tatiana Lyra Lima Félix}

tatianalyra@yahoo.com.br

Mestrado em Serviço Social pela Universidade Federal de Alagoas (UFAL)

Discente de doutorado do Programa de Pós-graduação em Serviço Social da Universidade Federal de Alagoas (UFAL)

\section{UFAL}

Campus A. C. Simões

Av. Lourival Melo Mota, S/N, Tabuleiro dos Martins, Maceió - Alagoas - Brasil

CEP 57072-970

\section{Agradecimentos}

Agradecemos aos trabalhadores e trabalhadoras da Casal pelos relevantes serviços prestados na luta contra a privatização da Companhia de Saneamento Básico de Alagoas.

Agência financiadora

Coordenação de Aperfeiçoamento de Pessoal de Nível Superior - Brasil (CAPES) - Código de Financiamento 001. Período de execução, desde agosto de 2017.

\section{Contribuições dos autores}

Os autores contribuíram conjuntamente na realização do manuscrito. Aprovação por Comitê de Ética

Não se aplica

Consentimento para publicação

Consentimentos dos autores.

Conflito de interesses

Não há conflito de interesses. 